\title{
Enhanced near-infrared photoluminescence from isoelectronic luminescent centers in sulfur-implanted silicon with copper or silver coimplantation
}

\author{
J. G. Zhang,, ${ }^{\text {a) }}$ X. X. Wang, B. W. Cheng, J. Z. Yu, and Q. M. Wang \\ State Key Laboratory on Integrated Optoelectronics, Institute of Semiconductors, \\ Chinese Academy of Sciences, Beijing 100083, People's Republic of China \\ J. Hau, L. Ding, and W. K. Ge \\ Physics Department, Hong Kong University of Science and Technology, Clear Water Bay, Kowloon, \\ Hong Kong, People's Republic of China
}

(Received 30 November 2006; accepted 9 January 2007; published online 20 February 2007)

\begin{abstract}
Enhanced near-infrared photoluminescence (PL) from sulfur-related isoelectronic luminescent centers in silicon was observed from thermally quenched sulfur-implanted silicon in which additional copper or silver ions had been coimplanted. The PL from the sulfur and copper coimplanted silicon peaked between 70 and $100 \mathrm{~K}$ and persisted to $260 \mathrm{~K}$. This result strongly supports the original conjecture from the optical detection of magnetic resonance studies that the strong PL from sulfur-doped silicon comes from $\mathrm{S}-\mathrm{Cu}$ isoelectronic complexes [Frens et al., Phys. Rev. B 46, 12316 (1992); Mason et al., ibid. 58, 7007 (1998).]. (C) 2007 American Institute of Physics. [DOI: 10.1063/1.2471673]
\end{abstract}

Since Brown and Hall's inaugurating work on strong near-infrared light emission from sulfur-doped silicon in $1986,{ }^{1,2}$ much work has been devoted to achieving highefficiency light emission from isoelectronic complexes in chalcogen-doped silicon ${ }^{3-6}$ and to characterizing the relevant atomic structure of the isoelectronic luminescent centers with the optical detection of magnetic resonance (ODMR) studies and other electronic spin resonance techniques. ${ }^{7-11}$ However, there were no new improved experimental results on highefficiency luminescence from sulfur-related isoelectronic centers in silicon for nearly two decades, until the dislocation loop was introduced to improve the luminescence of sulfurimplanted silicon by Homewood and co-workers in $2005 .^{12,13}$ It is difficult to perform moderate annealing for the formation of Ohmic contacts in devices without destroying the luminescence capability because the luminescence of the quenched samples will, in general, be completely quenched after annealing at temperatures higher than $200{ }^{\circ} \mathrm{C}$. Due to the high luminescence efficiency from sulfur-doped silicon, the capability of electrical excitation with low voltage, and the full compatibility with modern microelectronic technology, it would be worthwhile to pay more attention to the problem of how to increase the light emission efficiency and to achieve room temperature luminescence from sulfurdoped silicon. However, present research on silicon-based luminescence has centered mostly on silicon nanocrystals and rare earth ions. ${ }^{14}$

It is very important to know the exact composition of the luminescent isoelectronic complexes if more efficient luminescence is to be obtained from the isoelectronic pairs. A conjecture has been proposed from ODMR studies that the luminescent isoelectronic complexes from sulfur-doped silicon involve an atom with nuclear spin $I=3 / 2$. This impurity atom was assumed to be copper. ${ }^{7-11}$ Surprisingly, no intentional doping with copper atoms has been employed to see if copper codoping can increase luminescence from sulfurdoped silicon. In this work, we have achieved strongly en-

${ }^{a)}$ Electronic mail: jianguochang@yahoo.com hanced light emission from rapid thermally quenched sulfurdoped silicon into which additional copper or silver ions were coimplanted. The photoluminescence (PL) from sulfur and copper coimplanted silicon persists to $260 \mathrm{~K}$. It is believed that the complexes between chalcogen elements and group IB elements in silicon can constitute strong luminescent isoelectronic centers in silicon.

The samples were prepared by ion implantation of sulfur and group IB elements such as copper and silver in $n$-type Czochralski $(\mathrm{Cz})$ and float single crystal (100) silicon with a resistivities of $3-6$ and $\sim 1800 \Omega \mathrm{cm}$ at room temperature, respectively, with different implantation energies and doses. All implantation was conducted at an angle of $10^{\circ}$. Finally, the samples were annealed in air atmosphere for $5 \mathrm{~min}$. When the samples were taken out of the quartz furnace tube, the samples were quickly (in an interval less than $10 \mathrm{~s}$ ) thrown into 1:1 (in volume) de-ionized water and ethylene glycol miscible liquids. Then the samples were cleaned in de-ionized water and blown dry with high-purity nitrogen. Different annealing temperatures from 800 to $1200{ }^{\circ} \mathrm{C}$ were used, and temperatures around $1050{ }^{\circ} \mathrm{C}$ were found to maximize the PL intensity of the coimplanted silicons. The samples were also annealed in other different atmospheres such as nitrogen, oxygen, argon, or reducing gas for $5 \mathrm{~min}$, and it was found that there were no distinct differences among the different annealing atmospheres in PL intensity. Thus all samples described in letter paper were annealed in air atmosphere for $5 \mathrm{~min}$ at $1050{ }^{\circ} \mathrm{C}$ and were quenched in de-ionized water and ethylene glycol miscible liquids.

PL measurements were performed by pumping the samples with the $488 \mathrm{~nm}$ line of an $\mathrm{Ar}^{+}$-ion laser (Spectra Physics, stabilite 2016). The excitation power was fixed at $60 \mathrm{~mW}$ over a circular area of $\approx 0.1 \mathrm{~mm}^{2}$ (about $0.2 \mathrm{~mm}$ in radius), and the laser beam was mechanically chopped at a frequency of $273 \mathrm{~Hz}$. The PL signal was detected by a liquid-nitrogen-cooled Ge detector. Spectra were recorded with an $E G \& G$ 9530-SC lock-in amplifier with the chopper frequency as a reference. Low temperature measurements were performed using an APD closed-cycle liquid He cool- 


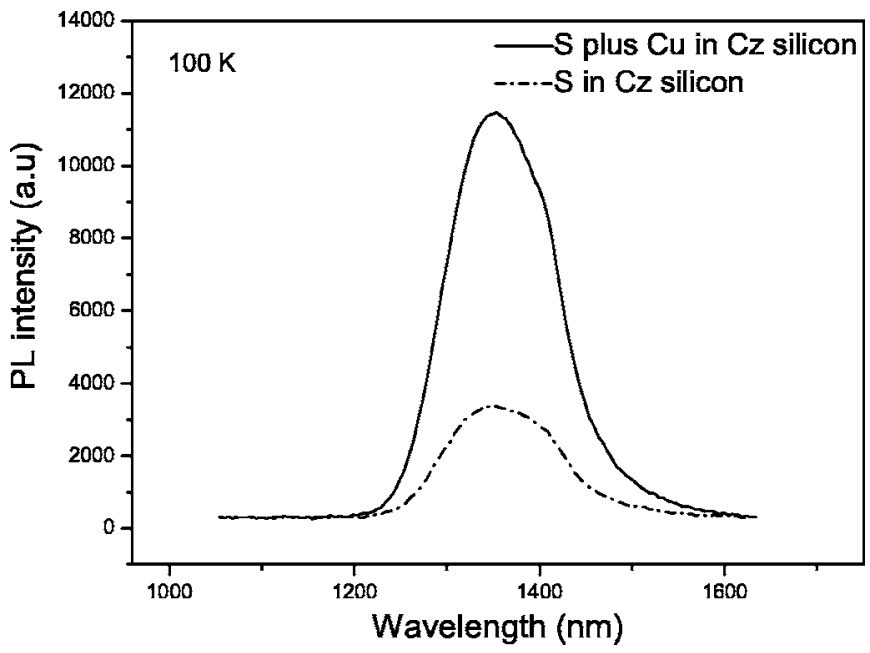

FIG. 1. PL spectra at $100 \mathrm{~K}$ for implanted $n$-type $\mathrm{Cz}$ silicon samples coimplanted with sulfur and copper ions. Sulfur ions were implanted at $265 \mathrm{keV}$ with a dose of $2 \times 10^{15}$ ions $/ \mathrm{cm}^{2}$. Copper ions were implanted at $450 \mathrm{keV}$ with a dose of $6.37 \times 10^{14}$ ions $/ \mathrm{cm}^{2}$.

ing system with the samples kept in vacuum. Because the PL intensity is strongly influenced by environmental factors such as outside light and previous measurements, all of the variable temperature PL measurements were performed in the dark and the temperature was increased to $100 \mathrm{~K}$ and then decreased to the measurement temperature after each measuremet.

Figure 1 shows typical PL spectra at $100 \mathrm{~K}$ for the sulfur and copper coimplanted and sulfur-only implanted $n$-type $\mathrm{Cz}$ silicon. According to the TRIM 98 code, ${ }^{15}$ sulfur and copper were implanted in silicon with a range depth of about $350 \mathrm{~nm}$, and the peak concentrations for sulfur and copper were about $9 \times 10^{19} 3 \times 10^{19}$ ions $/ \mathrm{cm}^{3}$, respectively. From the figure, it can be seen that the PL intensity of the sulfur and copper coimplanted $\mathrm{Cz}$ silicon is about four times that of the sulfur-only implanted $\mathrm{Cz}$ silicon. It must be pointed out that the PL intensity is strongly influenced by the quenching speed of the samples when the samples are annealed. We have performed six rounds of annealing of samples from the same sulfur-implanted silicon and compared their PL intensities. We found that the largest PL intensity of the samples is two and a half that of the smallest PL intensity of the samples. Thus it can be seen that sulfur and copper-doped silicon is much more efficient than sulfur-doped silicon. In fact, an enhancement of 20 times at most has been observed in PL intensity from our sulfur and copper coimplanted samples compared with that of sulfur-only implanted silicon.

Figure 2 shows typical PL spectra at $100 \mathrm{~K}$ for the sulfur and silver coimplanted and sulfur-only implanted $n$-type $\mathrm{Cz}$ and $n$-type float silicon. The PL intensity from coimplanted $\mathrm{Cz}$ or float silicon is much larger than that of sulfur-only implanted $\mathrm{Cz}$ or float silicon. It can be also seen that the enhancement factor for float silicon is much more obvious than that for $\mathrm{Cz}$ silicon, possibly due to the lower content of impurity such as copper atoms in the original float silicon and due to the lower absorption loss from impurities in the float silicon.

To characterize the optimal doping concentration for sulfur and copper coimplanted silicon, different doses of sulfur and copper were implanted in $\mathrm{Cz}$ silicon for comparison. Figure 3(a) shows the PL intensity evolution $(100 \mathrm{~K})$ for Downloaded 14 Sep 2007 to 143.89.106.174. Redistribution subje

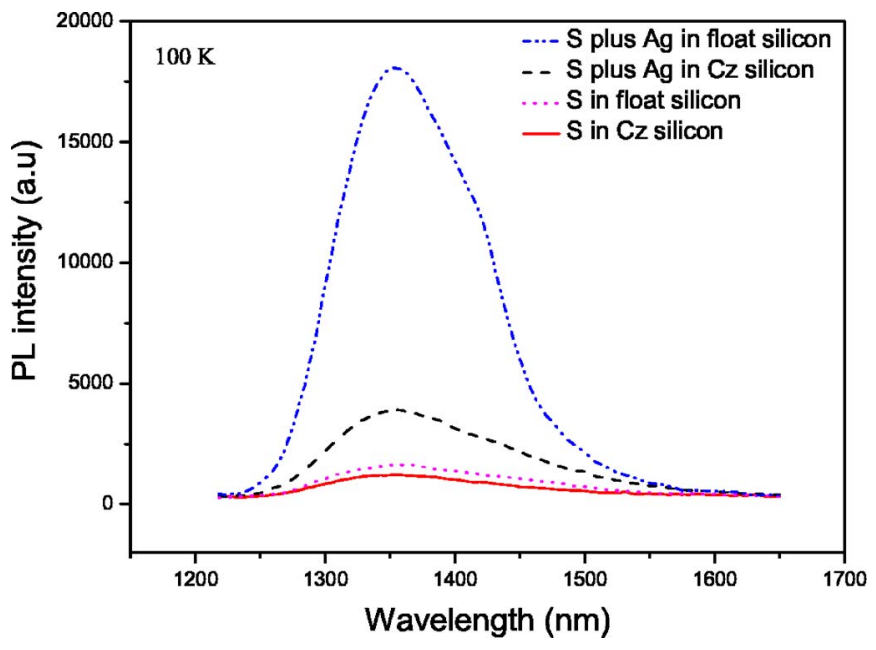

FIG. 2. (Color online) PL spectra at $100 \mathrm{~K}$ for implanted silicon samples coimplanted with sulfur and silver ions. Sulfur ions were implanted at $175 \mathrm{keV}$ with a dose of $1.5 \times 10^{15}$ ions $/ \mathrm{cm}^{2}$. Silver ions were implanted at $480 \mathrm{keV}$ with a dose of $9 \times 10^{14} \mathrm{ions} / \mathrm{cm}^{2}$.

samples into which the same dose of sulfur ions and different doses of copper ions were implanted. It can be seen that the optimal dose for copper implantation at $450 \mathrm{keV}$ is between $2 \times 10^{14}$ and $6 \times 10^{14}$ ions $/ \mathrm{cm}^{2}$. That is, the optimal peak concentration for copper implantation is between about $1 \times 10^{19}$ and $3 \times 10^{19} \mathrm{~cm}^{3}$ according to the TRIM 98 code. Figure 3(b) shows the PL intensity evolution for samples into which the same dose of copper ions and different doses of sulfur ions were implanted. It can be seen that the optimal dose for sulfur implantation at $265 \mathrm{keV}$ is $2.6 \times 10^{15}$ ions $/ \mathrm{cm}^{2}$. That is, the optimal peak concentration for sulfur implantation is about $1.0 \times 10^{20}$ ions $/ \mathrm{cm}^{2}$. However, one must keep in mind that the true concentration distribution for sulfur or copper ions after annealing is very different from the original distribution.

Figure 4 shows the temperature evolution of the PL intensity for sulfur and copper coimplanted $\mathrm{Cz}$ silicon. The sulfur and copper coimplanted silicon has the highest PL intensity at about $80 \mathrm{~K}$ and remains almost constant between 70 and $100 \mathrm{~K}$, so the coimplanted silicon can be considered to be a competent silicon light emitter at liquid-nitrogen tem-
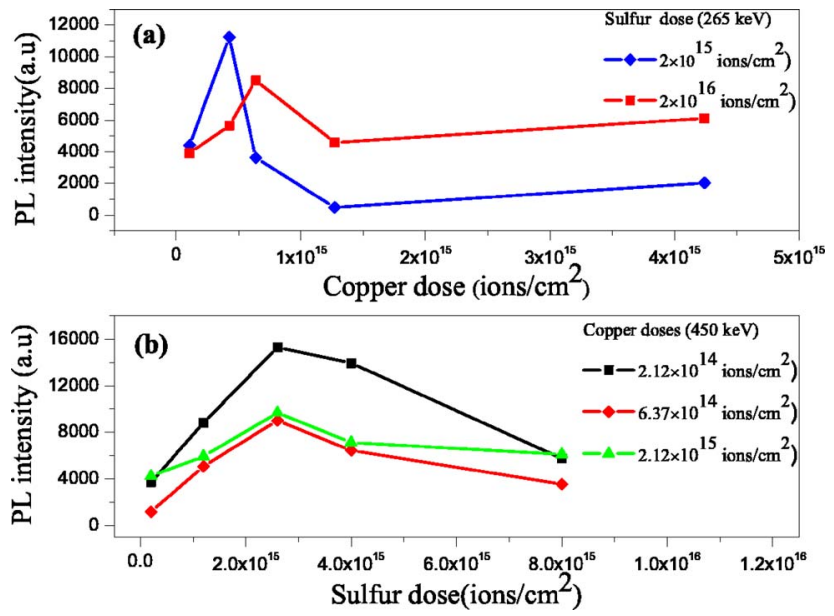

FIG. 3. (Color online) (a) PL intensity evolution (100 K) for samples in which the same dose of sulfur ions and different doses of copper ions were implanted. (b) The PL intensity evolution for samples in which the same dose of copper ions and different doses of sulfur ions were implanted. 


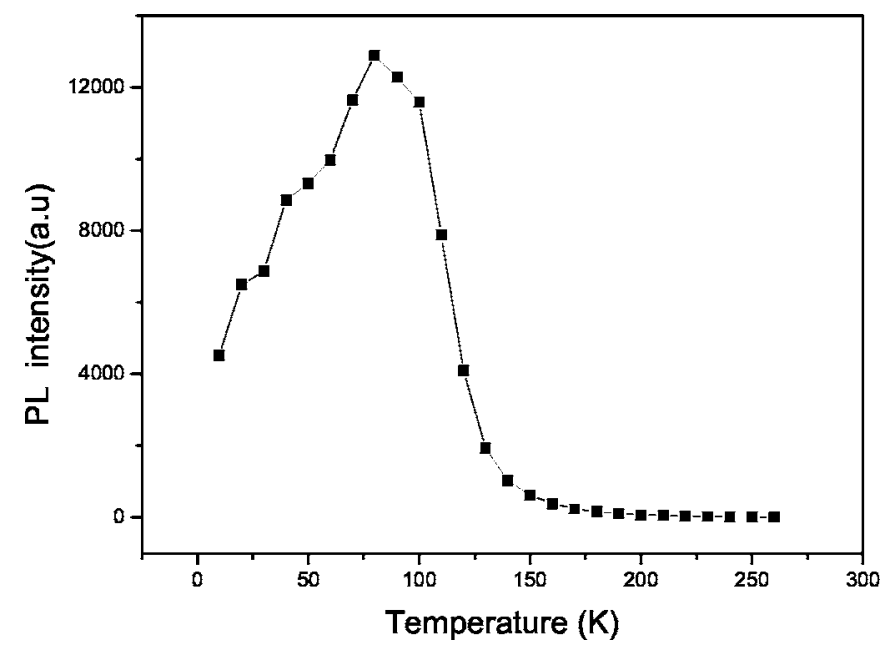

FIG. 4. Temperature evolution of PL intensity for sulfur and copper coimplanted $\mathrm{Cz}$ silicon. Sulfur was implanted at $265 \mathrm{keV}$ with a dose of 2 $\times 10^{15}$ ions $/ \mathrm{cm}^{2}$ and copper was implanted at $450 \mathrm{keV}$ with a dose of $6.37 \times 10^{14} \mathrm{ions} / \mathrm{cm}^{2}$.

perature. More surprisingly, the PL from the coimplanted $\mathrm{Cz}$ silicon persists to $260 \mathrm{~K}$. As a comparison, the sulfur-only implanted silicon can emit only at up to about $160 \mathrm{~K}^{1}$. As for the inner mechanism, it is possibly due to the increased concentration of isoelectronic pairs, which establishes the description by Brown and Hall in their US patent ${ }^{6}$ because it is the copper concentration that limits the concentration of the isoelectronic pairs in the sulfur-only implanted silicon. When sulfur and copper coimplantation is adopted, the concentration of the isoelectronic pairs increases correspondingly. It may be believed that if copper diffusion other than copper implantation as the doping method were adopted to dope the sulfur-doped silicon, the PL from $\mathrm{S}-\mathrm{Cu}$ isoelectronic luminescent pairs could persist to higher temperature, such as room temperature, because the limited implanted copper ions would quickly diffuse through the entire silicon substrate during annealing due to the large diffusion coefficient of copper atoms in silicon. On the other hand, if a large quantity of copper ions were implanted, the implantation-induced defects would retard the PL from the isoelectronic centers. Relevant research is under way.

In a previous report about PL from sulfur-doped silicon, ${ }^{1,2}$ oxygen was considered to play an important role, such as forming $\mathrm{S}-\mathrm{O}$ pairs, in increasing the PL intensity. However, annealing in different atmospheres gives no strong evidence for the enhancement effect. Oxygen was coimplanted intentionally in silicon with sulfur, and no enhancement occurred. In fact, due to the large difference between the bond energy of $\mathrm{Si}-\mathrm{O}$ and $\mathrm{Cu}-\mathrm{O}(2.7 \mathrm{eV}$ for $\mathrm{Cu}-\mathrm{O}$ and $8.0 \mathrm{eV}$ for $\mathrm{Si}-\mathrm{O}$ respectively), ${ }^{16}$ it is difficult for oxygen to form pairs with copper atoms in silicon.

In general, the characteristic PL line $(1.014 \mathrm{eV})$ from the copper-doped silicon can be found from the sulfur and copper codoped silicon. ${ }^{10}$ (Unfortunately, the resolved $1.014 \mathrm{eV}$ line was not found in our experiments due to the spectrometer's resolution.). Weber et al. gave a definite proof by using high resolution spectroscopy combined with uniaxial stress and Zeeman data that the intense emission at $1.014 \mathrm{eV}$ comes from substitutional copper $\left(\mathrm{Cu}_{s}\right)$-interstitial copper $\left(\mathrm{Cu}_{i}\right)$ pairs in copper-doped silicon. ${ }^{17}$ Vacancies were introduced into the silicon by the precipitation of copper or silver during the quenching, ${ }^{18}$ and part of the interstitial copper $\left(\mathrm{Cu}_{i}\right)$ or silver $\left(\mathrm{Ag}_{i}\right)$ atoms transferred substitutional copper $\left(\mathrm{Cu}_{s}\right)$ or silver $\left(\mathrm{Ag}_{s}\right)$ atoms by recombination between $\mathrm{Cu}_{i}$ and vacancies, or $\mathrm{Ag}_{i}$ and vacancies, forming $\mathrm{Cu}_{s}-\mathrm{Cu}_{i}$ pairs or $\mathrm{Ag}_{s}-\mathrm{Ag}_{i}$ pairs. It has been found that if no quenching is adopted, no PL can be found from the coimplanted silicons. Therefore, it may be thought that the isoelectronic pairs from coimplanted silicons are made up of sulfur atoms and $\mathrm{Cu}_{s}-\mathrm{Cu}_{i}$ pairs or of sulfur atoms and $\mathrm{Ag}_{s}-\mathrm{Ag}_{i}$ pairs.

In summary, sulfur and copper coimplanted silicon or sulfur and silver coimplanted silicon have been observed to achieve strongly enhanced near-infrared PL at liquidnitrogen temperature. The PL from sulfur and copper coimplanted silicon persists up to $260 \mathrm{~K}$. The original conjecture from ODMR studies that the strong near-infrared PL from sulfur-doped silicon is from $\mathrm{S}-\mathrm{Cu}$ complexes is validated experimentally.

This work was supported by the National Natural Science Foundation of China under Grant No. 60336010. The authors would like to express their gratitude to Olen Rambow for careful revisions of the English of the manuscript.

${ }^{1}$ T. G. Brown and D. G. Hall, Appl. Phys. Lett. 49, 245 (1986).

${ }^{2}$ T. G. Brown and D. G. Hall, in Light Emission in Silicon: From Physics to Devices, edited by D. J. Lockwood (Academic San Diego, CA, 1998), Vol. 49, p. 77.

${ }^{3}$ T. G. Brown, P. L. Bradfield, and D. G. Hall, Appl. Phys. Lett. 51, 1585 (1987).

${ }^{4}$ P. L. Bradfield, T. G. Brown, and D. G. Hall, Phys. Rev. B 38, 3533 (1988).

${ }^{5}$ P. L. Bradfield, T. G. Brown, and D. G. Hall, Appl. Phys. Lett. 55, 100 (1989).

${ }^{6}$ D. G. Hall and T. G. Brown, US Patent No. 4827318 (May 2, 1989).

${ }^{7}$ A. Henry, E. Sörman, S. Andersson, W. M. Chen, B. Monemar, and E. Janzén, Phys. Rev. B 49, 1662 (1994).

${ }^{8}$ D. J. S. Beckett, M. K. Nissen, and M. L. W. Thewalt, Phys. Rev. B 40, 9618 (1989).

${ }^{9}$ A. M. Frens, M. T. Bennebroek, J. Schmidt, W. M. Chen, and B. Monemar, Phys. Rev. B 46, 12316 (1992).

${ }^{10}$ P. W. Mason, H. J. Sun, B. Ittermann, S. S. Ostapenko, G. D. Watkins, L. Jeyanathan, M. Singh, G. Davies, and E. C. Lightowlers, Phys. Rev. B 58, 7007 (1998).

${ }^{11}$ E. Sörman, W. M. Chen, A. Henry, S. Andersson, E. Janzén, and B. Monemar, Phys. Rev. B 51, 2132 (1995).

${ }^{12}$ S. F. Galata, R. M. Gwilliam, and K. P. Homewod, Mater. Sci. Eng., B 124-125, 435 (2005).

${ }^{13}$ M. A. Lourenco, M. Milosavljevic, S. Galata, M. S. A. Siddiqui, G. Shao, R. M. Gwilliam, and K. P. Homewood, Vacuum 78, 551 (2005).

${ }^{14}$ See Symposium I: Silicon-Based Microphotonics, in MRS Proceedings, Vol. 934E, edited by M. Brongersma, D. S. Gardner, M. Lipson, and J. H. Shin (Materials Research Society, 2006). See special issue on Symposium D: Silicon-Based Photonics, in J. Lumin. 121, issue 2 , edited by J. Linnros, T. Gregorkiewicz, R. Elliman, and L. Kimerling (2006).

${ }^{15}$ J. F. Ziegler, J. P. Biersack, and U. Littmark, The Stopping and Range of Ions in Solids (Pergamon, New York, 1985).

${ }^{16}$ CRC Handbook of Chemistry and Physics: A Ready-Reference Book of Chemical and Physical Data, 82nd ed., edited by David R. Lide (CRC, Boca Raton, FL, 2001).

${ }^{17}$ J. Weber, H. Bauch, and R. Sauer, Phys. Rev. B 25, 7688 (1982).

${ }^{18}$ H. H. Woodbury and G. W. Ludwig, Phys. Rev. Lett. 5, 96 (1960). 